Supplement of

\title{
Enhanced hydrophobicity and volatility of submicron aerosols under severe emission control conditions in Beijing
}

\section{Yuying Wang et al.}

Correspondence to: Zhanqing Li (zli@atmos.umd.edu) and Fang Zhang (fang.zhang@bnu.edu.cn)

The copyright of individual parts of the supplement might differ from the CC-BY 3.0 licence. 
Table S1. Mean meteorological parameters during three periods

\begin{tabular}{cccc}
\hline & Clean1 & Clean2 & Pollution \\
\hline $\mathrm{WS}, 8{\mathrm{~m}\left(\mathrm{~m} \mathrm{~s}^{-1}\right)} 1.18$ & 1.64 & 1.07 \\
$\mathrm{~T}\left({ }^{\circ} \mathrm{C}\right)$ & 26.00 & 18.93 & 22.57 \\
$\mathrm{RH}(\%)$ & 57.32 & 52.77 & 62.14
\end{tabular}
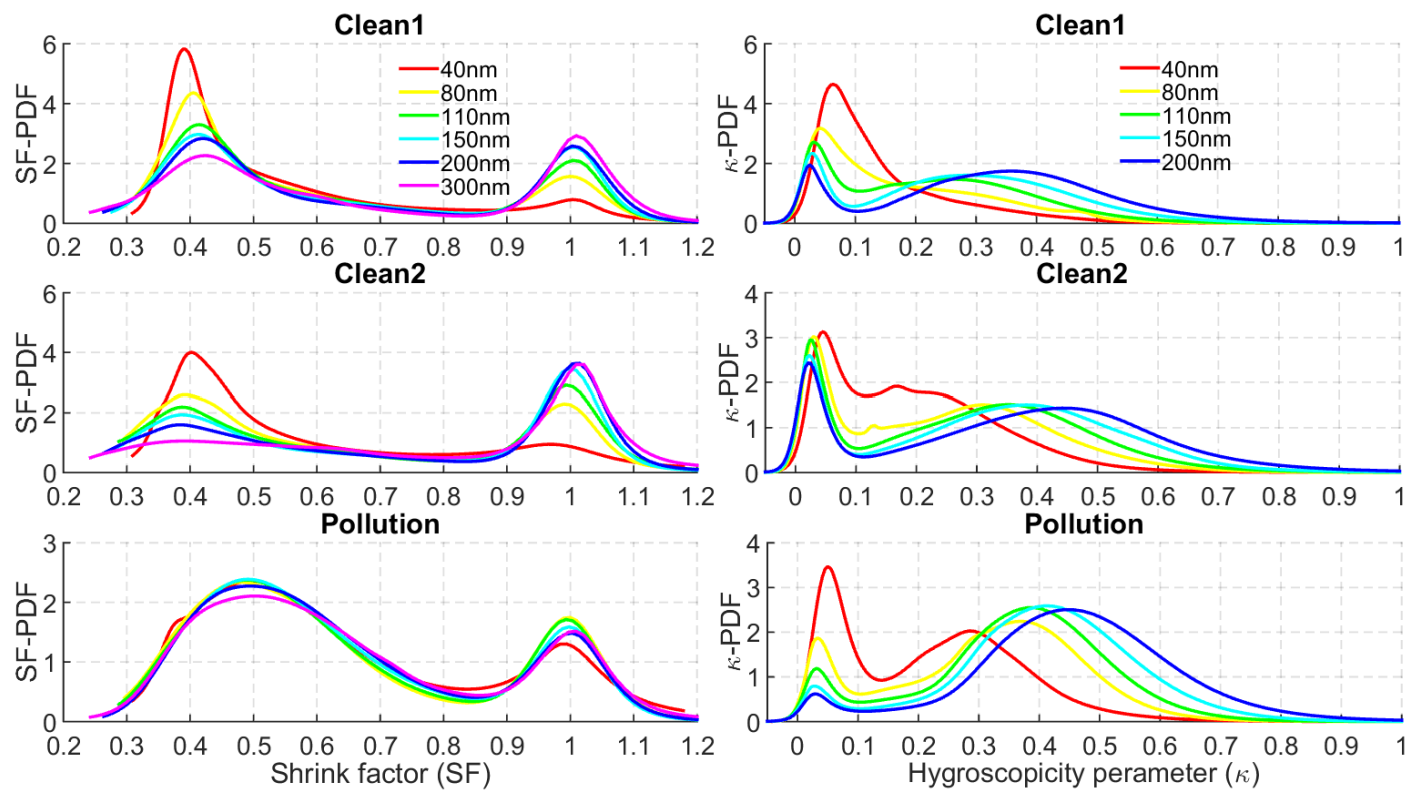

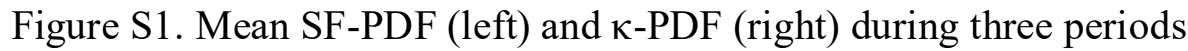
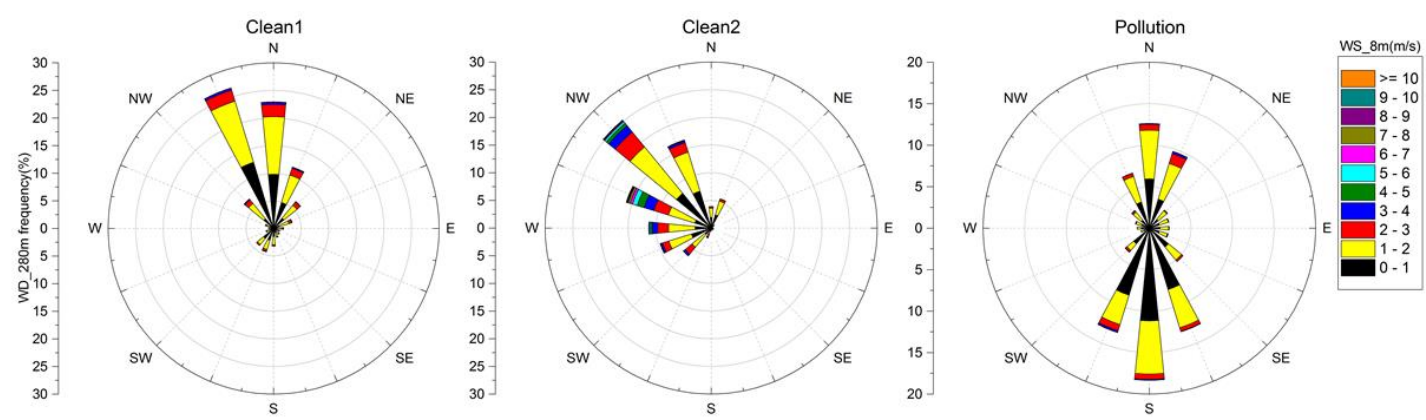

Figure S2. Wind rose diagram during three periods, color-coded by wind speed at $8 \mathrm{~m}$ for each period. The frequencies are set to the same scales but for wind direction at $280 \mathrm{~m}$. 

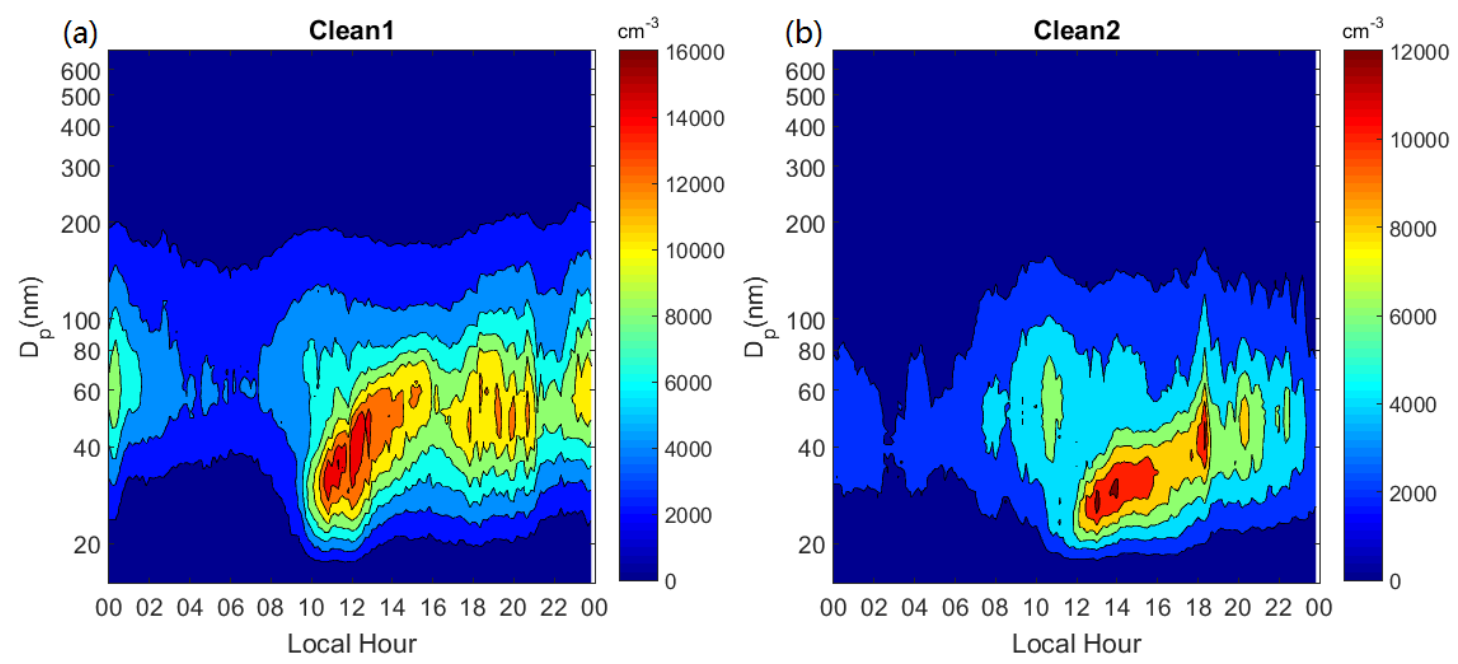

Figure S3. Diurnal variations in particle number size distribution at $260 \mathrm{~m}$ on the tower during (a) Clean1 and (b) Clean2 periods, the colored values are the size-resolved number concentrations $\left(\mathrm{dN} / \mathrm{d} \log \mathrm{D}_{\mathrm{p}}\right)$. 